\title{
Isomeric Forms of Biologically Active 2- Aminopyrimidinium Picrate Through Intrinsic Reaction Coordinate Analysis and Spectroscopic Measurements
}

\section{T. Karthick ( $\sim$ karthiphy84@gmail.com )}

Shanmugha Arts Science Technology and Research Academy School of Electrical and Electronics Engineering https://orcid.org/0000-0001-6029-8644

\section{Keshav Kumar Singh}

University of Lucknow Faculty of Science

\section{Swapnil Singh}

University of Wroclaw: Uniwersytet Wroclawski

Poonam Tandon

University of Lucknow Faculty of Science

\section{B. Narayana}

Mangalore University

\section{Research Article}

Keywords: 2-Aminopyrimidinium picrate, vibrational spectra, Intrinsic reaction coordinates, Charge delocalization, Non-covalent interactions

Posted Date: March 4th, 2021

DOl: https://doi.org/10.21203/rs.3.rs-264264/v1

License: () (1) This work is licensed under a Creative Commons Attribution 4.0 International License. Read Full License 


\section{Abstract}

In the present study, the isomeric forms of a biologically active 2-Aminopyrimidinium picrate cocrystal were investigated using spectroscopic investigation and Density functional theory (DFT) calculations. The vibrational assignments of IR and Raman peaks were predicted and the experimental IR and Raman spectra of the condensed phase of 2-Aminopyrimidinium picrate were compared with the simulated one. The intrinsic reaction coordinate (IRC) analysis was performed on all the possible reaction pathways to identify the isomeric forms of 2APP and transition state (TS) geometry. From the IRC analysis, a relatively stable form (named as isomer 2) has been identified in addition to the existing isomeric form (isomer 1) in the crystalline packing of 2APP. The presence of non-covalent interactions within the isomeric forms of 2APP was investigated with the help of quantum topological atoms in molecules (QTAIM) analysis. Reactivity descriptors and charge delocalization from lone pair to acceptor entities of both the isomers were predicted to validate the interactions present and to understand the charge distribution within the molecule.

\section{Introduction}

Picrates are well-known for their explosive properties and used as explosives during the first and second world wars. Picrates are also used to produce aniline; the most important starting material in chemical synthesis. While adding suitable cations to the picrate anions, biologically important picrate cocrystals are formed [1-34]. The biological applications of these picrates include anticancer, antitumor, antipsychotic drugs, etc. Cationic and anionic species in these picrate cocrystals are held together by strong hydrogen bonds. A biologically active 2-Aminopyrimidinium picrate (hereafter abbreviated as 2APP) molecule was crystallized by one of our co-workers Narayana and his colleagues [25] and resolved its Xray crystallography data. Also, Jasinski and coworkers have synthesized biologically active picrates such as Lomefloxacinium picrate [28], Acetylpiperazinium picrate [34] and 1-(2-Methyl-5nitrophenyl)guanidinium picrate [7] and resolved their crystalline structures. In the present work, the structural properties of 2APP at the atomic level were predicted using spectroscopic techniques and quantum chemical computations. Moreover, the reaction pathways and possible structural isomers were investigated using density functional theory (DFT) computations. The spectroscopic studies were carried out to verify the conformations of 2APP in the crystalline geometry. In general, the biologically active molecules bind with the macromolecular targets through hydrogen bonds between the electron donor and acceptor species of the ligand and targets. It is necessary to find the electrophilic and nucleophilic sites of the ligand to understand the binding mechanisms. Hence, the Fukui functions analysis was performed to reveal the relative electrophilicity and nucleophilicity of 2APP.

\section{Experimental}

The compound 2APP was synthesized by conventional synthesis procedures [25]. A yellow color crystalline sample of 2APP approximately $1 \mathrm{mg}$ with potassium bromide $(\mathrm{KBr})$ reference material in the ratio of 1:200 (2APP: KBr) were ground well for 15 mins. Using a hydraulic press, a disc-shaped pellet of 
the sample-reference mixer was made. Fourier transform IR spectrum (FT-IR) of 2APP was recorded in the mid-IR region from 4000 to $450 \mathrm{~cm}^{-1}$ on a Perkin Elmer Spectrum One FT-IR instrument with a spectral resolution of $1 \mathrm{~cm}^{-1}$. The Raman spectrum of 2APP was measured at room temperature in a Horiba LabRaman spectrometer equipped with a liquid N2-cooled CCD detector. The spectrometer slits were set for a resolution of $2 \mathrm{~cm}^{-1}$. A He-Ne laser of $633 \mathrm{~nm}$ line was used as an excitation source.

\section{Methodology}

To study the structure and related properties of 2APP, the electronic structure calculations were performed using the Gaussian 16 suite of ab initio program [35]. The electronic structure of 2APP is optimized to the minimum energy using the density functional WB97XD with $6-311++G(d, p)$ basis set [36]. WB97XD functional is expected to provide accurate geometry as it includes Grimmes second-order dispersion corrections in its definition. The inclusion of London dispersion forces is very important in describing the molecular structure showing hydrogen bonds with its neighbours. The analytical frequency calculations have been performed on the optimized geometry of 2APP to confirm the nature of stationary point as minima as well as to simulate the mid-infrared (IR) and Raman spectra. The transition states (TS) geometry search has been performed using a quadratic synchronous transit (QST2) approach to investigate the potential energy surface (PES) to locate the different isomers of 2APP and transition states (TS) that exists between the isomers. Full of positive harmonic frequencies obtained in the calculation for both the isomers validate their stationary point minima on the PES and TS structure with one non-negligible imaginary frequency confirms the stationary point maxima on the PES. Intrinsic reaction coordinates (IRC) were calculated to ensure whether the TS structure acts as an intermediate for both the reactant and product [37, 38]. The spectra generated from the analytical frequency calculations were scaled down using the wavenumber linear scaling (WLS) method [39] to overcome the overestimation of results due to the neglect of anharmonic vibrations. To calculate the local reactivity descriptor and Fukui functions, the partial charges on individual atoms were calculated via Hirshfeld population analysis [40] at $w B 97 X D / 6-31++G(d, p)$.

\section{Results And Discussion}

\subsection{Intrinsic reaction coordinate analysis and classification of isomers}

The crystal structure of 2APP is optimized at wB97XD/6-311 ++G(d,p) level of approximation and the optimized structure of 2APP (hereafter abbreviate as isomer 1) and presented in Fig. 1. The coplanar structures of picrate (Ring 1) and pyrimidine (Ring 2) molecules in isomer1 (total energy $=-1240.3495$ Hartree, herein total energy = electronic energy + zero point vibrational energy corrections) during the optimization are not much varied which confirms the cocrystal formation through higher binding energy. In isomer 1 , the pyrimidine ring has $\mathrm{NH}_{2}$ group and $\mathrm{N}-\mathrm{H}$ bond and they facilitate to bond with picrate ring 
through $\mathrm{N}-\mathrm{H} \cdots \mathrm{O}$ hydrogen bonds. The crystal structure of isomer 1 is predicted to be a polar molecule where ring 2 donates some of its charges to the ring 1 and forms an anionic-cationic system.

To understand the chemical reactivity of isomer 1 , local reactivity descriptors were calculated at the WB97XD/6-311 ++ G (d, p) level of theory. The local reactivity descriptors are important tools to predict the possible binding sites of a particular reaction complex[41, 42]. The picrate molecule (ring 1 ) of isomer 1 is a highly reactive compound with strong nucleophilic sites such as 025,026 and 031 . The Fukui descriptors $\mathrm{s}^{+}$and $\mathrm{s}$ of isomer 1 and 2 represent the sites prone to nucleophile and electrophilic attack and are tabulated in Tables S1 and S2 (Supplementary Information). Among 025, 26 and 031, the 025 has strong nucleophile character $\left(\mathrm{s}^{-}=0.6523 \mathrm{a}\right.$.u) as compared to the other reactive sites of the ring 1 i.e. $\mathrm{O}_{26}\left(\mathrm{~s}^{-}=0.1922 \mathrm{a} . \mathrm{u}\right)$ and $031\left(\mathrm{~s}^{-}=0.1966 \mathrm{a}\right.$.u $)$. On the other hand, there are two atoms of hydrogen (H3 and $\mathrm{H} 6$ ) on the pyrimidine ring (ring 2) in the vicinity of the 025 are prone to the attack by 025 . Hence, the atom 025 makes strong hydrogen bonds $025 \cdots \mathrm{H} 6(1.6261 \AA)$ and $025 \cdots \mathrm{H} 3(1.9656 \AA)$. A ring 2 in isomer 1 is a heterocyclic six-membered ring that holds strongly electronegative nitrogen atoms N5 and N13. This results in the less nucleophile character of the heterocyclic ring as the nitrogen atoms withdraw the majority of the electron density towards themselves [43]. Additionally, the amine group $\left(\mathrm{N}_{1} \mathrm{H}_{2}\right)$ at $\mathrm{C} 2$ position also withdraws some of the electron density. This behavior makes the hydrogen of the N5H6 group strongly positive as nitrogen $\mathrm{N} 5$ strip electron form $\mathrm{H} 6$ and ring is also depleted from the electron density and hence cannot act as an electron donor. These considerations make the $\mathrm{H} 6$ a stronger electrophilic as compared to $\mathrm{H} 3$ of the ring 2 in the isomer 1.

Additionally, the 025 carries the largest negative partial charge in the isomer $1(-0.273 e)$ while $\mathrm{H} 6$ carries the largest positive charge among all the hydrogen in the isomer $1(0.098 \mathrm{e})$. This charge difference creates a strong electrostatic interaction between 025 and H6. Thus, oxygen 025 donates one of its lone pair electrons to the $\mathrm{H} 6$ inducing a heterolithic dissociation in the $\mathrm{N} 5 \mathrm{H} 6$ bond of ring 2 . The free hydrogen $\mathrm{H} 6$ then makes a covalent bond with 025 and forms the product (isomer 2, total energy $=-1240.4037$ Hartree) as shown in Fig. 2. The enthalpy of the formation from isomer 1 to isomer 2 is calculated at about $15.22298 \mathrm{~kJ} / \mathrm{mol}$ with respect to the isomer 1 . This represents an endogenic isomerization with activation energy ( $3.6777 \mathrm{~kJ} / \mathrm{mol}$, transition state total energy $=-1240.4059$ Hartree) (Fig. 3). Since very small energy is required to change isomer 1 into isomer 2 and isomerization is very slightly endogenic, it is expected that both isomers exist in thermodynamic equilibrium at room temperature.

There is one more possibility of isomerization in this system. The nucleophilic site 025 can donate its lone pair electrons to the hydrogen $\mathrm{H} 3$. The local minima structure along this root is studied by breaking up of the bond $\mathrm{N} 1 \mathrm{H} 3$ and forming $\mathrm{O} 25 \mathrm{H} 3$ bond manually followed by optimization. However, when this structure is optimized, hydrogen $\mathrm{H} 3$ always tend to move back to N1. Since no local minima could be located for this root, we propose that the local minima structure along this root is not feasible. The primary reason for this would be the instability of the amino group $\left(\mathrm{N}^{1} \mathrm{H}_{2}\right)$ at $\mathrm{C} 2$ for proton transfer to 026. Additionally, the distance between the 025 and H3 is large (1.9656 $\AA$ ) compared to the distance 
between 025 and $\mathrm{H} 6(1.6261 \AA$ $)$. Hence, the electron transfer is more feasible between 025 and $\mathrm{H} 6$ than between $\mathrm{O} 25$ and $\mathrm{H} 3$.

The isomer 2 has similar structure as isomer 1. Besides the hydrogen transfer from N5 to 025, a slight out of plane shift of pyrimidine ring from the planer structure of isomer 1. The reason for this shift has been explained in the following paragraph. After the formation of isomer 2, the distance between the $\mathrm{H} 3$ and $\mathrm{O} 25$ has increased and becomes $2.3315 \AA$ while distance between $\mathrm{H} 6$ (now attached to 025) and N5 becomes $1.5348 \AA$ (Fig. 2). The change in distances is due to the out of plane shift of pyrimidine ring from the planer structure of isomer 1 . The new structure that the previous hydrogen bond $\mathrm{H} 3 \cdots 025$ has now becomes weak due to increases in the distance of donor and accepter atoms and a new hydrogen bond $\mathrm{H} 6 \cdots \mathrm{N} 5$ has formed. The HOMO-LUMO energy gap for the isomer 1 and 2 is observed to be 0.2245 0.2808 au respectively. This shows that isomer 2 is less reactive compared to isomer 1 . The reason for this less reactivity is that after the formation of isomer 2, the HOMO of the isomer 2 is completely shifted from pictrate ring to the pyrimidine ring. Now whatever electron density pyrimidine ring gain form the transfer of $\mathrm{H} 6$ to the pictrate ring, it is distribute that throughout the ring. This will ingresses the stability of the pyrimidine ring and of isomer 2 in general and decrees the overall reactivity of isomer 2.

To reveal more about the mechanism for the formation of isomer 2 from the 1, we picked equidistance points on the IRC (that includes TS) and performed single-point energy calculations on each point. This provides us the wave functions of that particular structure which helps to see the structural changes during the reaction as well as the change in the molecular orbitals and charge delocalization upon the change in the energy. The highest occupied molecular orbitals (HOMO) of these intermediate points are displayed in Fig. 4. Form point 3 it can be seen that the electron cloud of the highest occupied orbital is mostly contained over the picrate ring and over oxygen atoms attached to this ring which is because the picrate ring is a homogenous carbon ring having much of its electron density in the $\pi$ electron cloud and some of its electron density is contained exposed lone pair electrons in the oxygen atoms. When one electron pair is transferred from the oxygen atom to the nearest hydrogen, it induces a proton transfer, while the hydrogen leaving the $-\mathrm{NH}$ group of pyrimidine ring gives back its electron involved in the $\mathrm{NH}$ bonding. This electron goes back to the pyrimidine ring and thus shifting the $\mathrm{HOMO}$ to the pyrimidine ring (point 0 to -2). After completing the reaction, the electron cloud in the pyrimidine ring will start repelling the nearest oxygen atoms results in the slight out of the plane tilt of picrate ring in the product complex (point - 2).

\subsection{Electron density distribution}

Analysis of electron density distribution is a straightforward approach to unravel the hydrogen bonding interactions between the electron donor and acceptor species of the electronic structure of the molecule or cocrystals. Quantum topological atoms in molecules (QTAIM) [44] offers an elegant approach that provides pictorial evidence to the hydrogen bonding interactions in terms of line critical points (LCP) and the type and strength of the interactions can be characterized by quantum topological parameters such as electron density $(\rho(r))$, Laplacian of electron density $\left(\nabla^{2} \rho(r)\right)$, bond ellipticity $(\varepsilon)$ and hydrogen bond 
(HB) energies $\left(\mathrm{E}_{\mathrm{HB}}\right)$. The quantum topological descriptors of isomer 1 and 2 are collected in Table 1 and molecular graphs are presented in Fig. 5.

According to Bader's theory of QTAIM, the value of $\rho(r)$ is quite small $\left(\sim 10^{-2}\right.$ a.u. or less for $\mathrm{H}$-bonded complexes and $10^{-3}$ a.u. for van der Waals complexes) and $\nabla^{2} \rho(r)$ is positive. The predicted topological parameters of the intermolecular interactions for isomer 1 and 2 are within the range of $\mathrm{H}$-bonded complexes as given by Bader. The intermolecular interactions such as $026 \cdots \mathrm{H} 8,025 \cdots \mathrm{H} 3,031 \cdots \mathrm{H} 3$, $031 \cdots 025,025 \cdots 026$ commonly exist in both the isomers, among them $031 \cdots 025,025 \cdots 026$ are nonclassical hydrogen bonds. The prominent intermolecular interactions $025 \cdots \mathrm{H} 6$ (isomer 1 ) and $\mathrm{N} 5 \cdots \mathrm{H} 6$ (isomer 2) discriminate the isomeric forms of 2APP. The calculated binding energy of complexes in isomer 1 and isomer 2 are $171.88 \mathrm{~kJ} / \mathrm{mol}$ and $168.82 \mathrm{~kJ} / \mathrm{mol}$ respectively. The difference in the binding energy of the complexes isomer 1 and 2 are calculated as $3.06 \mathrm{~kJ} / \mathrm{mol}$. The bond ellipticity $(\varepsilon)$ measures the extent to which electron density $(\rho(r))$ is accumulated in a given plane containing the bond path [45]. The higher value of $\varepsilon$ illustrates the structural instability and its value close to zero represents the bond is cylindrically symmetrical [46]. Hence, the lesser $\varepsilon$ value and higher hydrogen bonding energy $\left(E_{H B}\right)$ for the interactions $025 \cdots \mathrm{H} 3$ and $025 \cdots \mathrm{H} 6$ are more prominent interactions of isomer 1 while in isomer $2, \mathrm{~N} 5 \cdots \mathrm{H} 6$ is the most prominent interaction. 
Table 1

QTAIM parameters of non-bonded classical/non-classical HBs isomer 1 and isomer 2 of 2APP.

\begin{tabular}{|c|c|c|c|c|c|c|c|}
\hline $\begin{array}{l}\text { Classical/ } \\
\text { Non-classical } \\
\text { HBs }\end{array}$ & Bond & $\begin{array}{l}\text { Bond } \\
\text { distance }\end{array}$ & $\begin{array}{l}\text { electron } \\
\text { density }\end{array}$ & $\begin{array}{l}\text { Laplacian of } \\
\text { electron } \\
\text { density }\end{array}$ & $\begin{array}{l}\text { Bond } \\
\text { ellipticity }\end{array}$ & $\mathrm{E}_{\mathrm{HB}}$ & $\begin{array}{l}\text { Binding } \\
\text { Energy }\end{array}$ \\
\hline \multicolumn{8}{|l|}{ isomer 1} \\
\hline Classical & $\mathrm{O} 26 \cdots \mathrm{H} 6$ & 2.1760 & 0.0158 & 0.0651 & 1.17 & 15.49 & \multirow[t]{7}{*}{171.88} \\
\hline Classical & $\mathrm{O} 26 \cdots \mathrm{H} 8$ & 2.3702 & 0.0104 & 0.0445 & 0.35 & 9.29 & \\
\hline Classical & $\mathrm{O} 25 \cdots \mathrm{H} 3$ & 1.9656 & 0.0244 & 0.0967 & 0.06 & 25.06 & \\
\hline Classical & $\mathrm{O} 25 \cdots \mathrm{H} 6$ & 1.6261 & 0.0531 & 0.1608 & 0.03 & 71.56 & \\
\hline Classical & $\mathrm{O} 31 \cdots \mathrm{H} 3$ & 2.0859 & 0.0165 & 0.0690 & 0.13 & 15.29 & \\
\hline non-classical & $031 \cdots 025$ & 2.6940 & 0.0168 & 0.0627 & 0.23 & 17.43 & \\
\hline non-classical & $025 \cdots 026$ & 2.6958 & 0.0172 & 0.0638 & 0.48 & 17.76 & \\
\hline \multicolumn{8}{|l|}{ isomer 2} \\
\hline Classical & $\mathrm{O} 26 \cdots \mathrm{H} 8$ & 2.3770 & 0.0114 & 0.0405 & 0.16 & 9.47 & \multirow[t]{6}{*}{168.82} \\
\hline Classical & $\mathrm{O} 25 \cdots \mathrm{H} 3$ & 2.3315 & 0.0117 & 0.0434 & 0.33 & 10.19 & \\
\hline Classical & $\mathrm{N} 5 \cdots \mathrm{H} 6$ & 1.5348 & 0.0818 & 0.0847 & 0.03 & 110.87 & \\
\hline Classical & $\mathrm{O} 31 \cdots \mathrm{H} 3$ & 2.2363 & 0.0119 & 0.0456 & 0.04 & 9.66 & \\
\hline non-classical & $031 \cdots 025$ & 2.7417 & 0.0144 & 0.0563 & 0.39 & 15.04 & \\
\hline non-classical & $025 \cdots 026$ & 2.7963 & 0.0132 & 0.0533 & 0.83 & 13.59 & \\
\hline
\end{tabular}

\subsection{Evidence from natural bond orbitals}

The second-order perturbation energies concerning the donor $\rightarrow$ acceptor entities of both the isomers were predicted by natural bond orbital analysis and the results were depicted in Table S3 and S4. The donor $\rightarrow$ acceptor entities of isomer 1 such as LP(2)O25 $\rightarrow \mathrm{BD} *(1) \mathrm{N} 5-\mathrm{H} 6$ and LP(1)O25 $\rightarrow \mathrm{BD} *(1) \mathrm{N} 5-\mathrm{H} 6$ with the stabilization energies of 26.81 and $14.15 \mathrm{kcal} / \mathrm{mol}$ confirms the non-bonded interaction $025 \cdots \mathrm{H} 6$. The stabilization energies of $6.7 \mathrm{kcal} / \mathrm{mol}$ predicted for $\mathrm{LP}(1) \mathrm{O} 25 \rightarrow \mathrm{BD} *(1) \mathrm{N} 1-\mathrm{H} 3$ confirms the non-bonded interaction $025 \cdots \mathrm{H} 3$. Moreover, a prominent interaction $\mathrm{N} 5 \cdots \mathrm{H} 6$ which confirms the presence of isomer 2 is also identified from NBO analysis. $\mathrm{LP}(1) \mathrm{N} 5 \rightarrow \mathrm{BD} *(1) \mathrm{O} 25-\mathrm{H} 6$ with noticeable stabilization energy of about $109.56 \mathrm{kcal} / \mathrm{mol}$ supports the presence of non-bonded interaction $\mathrm{N} 5 \cdots \mathrm{H} 6$. Apart from these prominent interactions, the donor $\rightarrow$ acceptor entities of the rest of the molecule were also collected in Table S3 and S4.

\subsection{Analysis of vibration spectra}


To confirm the isomeric conformation in the solid phase, the Fourier-transform mid-IR and Raman spectra of both the isomers of 2APP were recorded and the observed results were compared with their respective theoretically simulated spectra (see, Figs. 6 and 7). The assignment of the peaks was confirmed with the aid of potential energy distribution (PED) results. A broad and very weak intensity band in the region 3850 to $3650 \mathrm{~cm}^{-1}$ in the FT-IR spectrum are recognized as $\mathrm{N}-\mathrm{H}$ stretching vibrations of the amino group of picrate [47]. The scaled wavenumbers of 3772 and $3646 \mathrm{~cm}^{-1}$ for isomer 2 and 3529 and $3274 \mathrm{~cm}^{-1}$ for isomer 1 are ascribed to $\mathrm{N}-\mathrm{H}$ stretching vibrations of the amino group. It reflects that the stretching modes of $\mathrm{N}-\mathrm{H}$ bonds in the amino group are greatly affected upon the transfer of hydrogen atom from the pyrimidine ring to picrate ring (from isomer 1 to isomer 2 conversion). The conformational isomerism of 2APP could be identified by the careful investigation of N5-H6 (isomer 1) and 025- H6 (isomer 2) stretching bands. The presence of $\mathrm{N} 5-\mathrm{H} 6$ stretching band and absence of $\mathrm{O} 25-\mathrm{H} 6$ bond confirms isomer 1 of 2APP and the absence of $\mathrm{N} 5-\mathrm{H} 6$ stretching band and the presence of $\mathrm{O} 25-\mathrm{H} 6$ bond confirms isomer 2 of 2APP. A peak identified at $3437 \mathrm{~cm}^{-1}$ belongs to intermolecular $025 \cdots \mathrm{H} 6$ stretching mode and the N5-H6 stretching peak centered at $2913 \mathrm{~cm}^{-1}$ in the FT-IR confirms the structure of isomer 1 . The assignments of all the vibrational modes of isomers 1 and 2 are given in Tables S5 and S6 (Supplementary Material) respectively.

Our spectroscopic investigations along with theoretical calculations shed light on the structural insights of isomers 1 and 2. We have seen a broad small peak of $\mathrm{NH}$ stretching at $2835 \mathrm{~cm}^{-1}$ in isomer 1. It's quite evident $\mathrm{N} 5 \mathrm{H} 6$ of pyrimidine molecule is involved in the formation of intermolecular $\mathrm{H}$-bonding with an Oxygen atom (025) of picrate molecule. On the other hand, we have not seen such spectroscopic features (IR and Raman) in isomer 1. Similarly, we have observed the $025 \mathrm{H} 6$ stretching at $3106 \mathrm{~cm}^{-1}$ in isomer 2 which signifies $\mathrm{OH}$ of picrate molecule is involved in $\mathrm{H}$-bonding with a nitrogen atom (N5) of pyrimidine molecule while such traces are completely missing in isomer 1 . Additionally, $\mathrm{C}=\mathrm{O}$ stretching in both the isomers 1 and 2 were found at 1545 and $1534 \mathrm{~cm}^{-1}$, respectively which suggests $C=0$ involved in the formation of intermolecular H-bonding. Thus, our spectroscopic results confirmed the theoretical findings and support our predicted molecular structure.

\section{Conclusion}

In the present work, the possible isomerization of 2-Aminopyrimidinium picrate cocrystal and reactivity descriptors of isomers were investigated using vibrational spectra and density functional theory computations. The reaction pathway from isomer 1 to isomer 2 through the transition state structure of 2APP has been proposed and the changes in the electron density of atoms on the intermediary points from the reactants to product were investigated to observe the structure changes upon isomerization. With the help of QTAIM, the non-bonded interactions between the pyrimidine and picrate rings were identified and the strength of the bonds were analyzed by quantum topological descriptors viz. electron density, Laplacian of electron density, bond ellipticity and hydrogen bond energy. The charge delocalization between various donor and acceptor entities of pyrimidine and picrate rings were investigated by NBO analysis and the site prone to electrophilic and nucleophilic attacks were identified by Fukui descriptors. The detailed vibrational assignments of all the harmonic frequencies were predicted 
and the simulated IR and Raman spectra were compared with the experimental FT-IR and FT-Raman to validate the presence of isomers.

\section{Declarations}

\section{Acknowledgment}

T. Karthick acknowledges the management of SASTRA Deemed University, Thanjavur, Tamil Nadu, and India for providing necessary infrastructure and computational facilities. The financial Support to K.K. Singh and P. Tandon from Science \& Engineering Research Board (SERB), Department of Science \& Technology, and Government of India (Grant no. CRG/2019/006671) is gratefully acknowledged.

\section{Funding information}

This work was supported by Science \& Engineering Research Board (SERB), Department of Science \& Technology, and Government of India, Grant no. CRG/2019/006671. Recipient: Prof. Poonam Tandon.

\section{Conflicts of interest/Competing interests}

The authors have no conflicts of interest/competing interests to disclose.

\section{Availability of data and material (data transparency)}

$\mathrm{N} / \mathrm{A}$

Code availability (software application or custom code)

N/A

\section{Authors' contributions (include appropriate statements)}

T. Karthick - made substantial contributions to the conception or design of the work, data acquisition, analysis, and interpretation of data in the work.

Keshav Kumar Singh - made significant contribution in drafting some part of the work

Swapnil Singh - made contributions in the data acquisition and analysis

Poonam Tandon - revised the draft critically for important intellectual content

B. Narayana - made contribution in the synthesis of the compound.

\section{References}


1. Jasinski JP, Butcher RJ, Hakim Al-Arique QNM, Yathirajan HS, Narayana B (Sep. 2009) 4-(4-Chlorophen-yl)-1-[3-(4-fluoro-benzo-yl)prop-yl]-4-hydroxy-piperidin-1-ium 2,4,6-trinitro-phenolate (haloperidol picrate). Acta Crystallogr Sect E Struct Rep Online 65:no. Pt 10, pp. o2403-o2404.

doi:10.1107/S1600536809033261

2. Yathirajan HS, Ashok MA, Narayana Achar B, Bolte M (Mar. 2007) Promazinium picrate. Acta Crystallogr Sect E 63(3):01432-01434. doi:https://doi.org/10.1107/S1600536807008306

3. Jasinski JP, Butcher RJ, Yathirajan HS, Mallesha L, Mohana KN, “4-[(E)-(2,4-Difluoro-phen-yl)(hydroxyimino)meth-yl]piperidinium picrate," Acta Crystallogr. Sect. E. Struct. Rep. Online, vol. 65, no. Pt 10, pp. o2365-o2366, Sep. 2009, doi: 10.1107/S1600536809035363

4. Yathirajan HS, Ashok MA, Narayana Achar B, Bolte M (Apr. 2007) Ethopropazinium picrate. Acta Crystallogr Sect E 63(4):01792-01794. doi:https://doi.org/10.1107/S1600536807011543

5. Kant R, Kohli S, Sarmal L, Narayana B, Samshuddin S, “4-(2-Chloro-ethyl)morpholinium picrate," Acta Crystallogr. Sect. E. Struct. Rep. Online, vol. 65, no. Pt 10, pp. 02435-o2435, Sep. 2009, doi:

10.1107/S1600536809035405

6. Sarojini BK, Narayana B, Swamy MT, Yathirajan HS, Bolte M (Oct. 2007) 5-Bromo-3-

(methylaminocarbonyl)pyridinium picrate. Acta Crystallogr Sect E 63(10):04181-04181.

doi:https://doi.org/10.1107/S1600536807046934

7. Jasinski JP, Butcher RJ, Swamy MT, Yathirajan HS, Ramesha AR (Oct. 2009) 1-(2-Methyl-5-nitrophenyl)guanidinium picrate. Acta Crystallogr Sect E Struct Rep Online 65:no. Pt 11, pp. o2788o2789. doi:10.1107/S1600536809037647

8. Jasinski JP, Butcher RJ, Yathirajan HS, Mallesha L, Mohana KN, "4-[(E)-(2,4-Difluoro-phen-yl)(hydroxyimino)meth-yl]piperidinium picrate," Acta Crystallogr Sect E Struct Reports Online, 65, 10, 2009, doi:10.1107/S1600536809035363

9. Yathirajan HS, Ashok MA, Narayana Achar B, Bolte M (Apr. 2007) Mepazinium picrate. Acta Crystallogr Sect E 63(4):01691-01692. doi:https://doi.org/10.1107/S1600536807009877

10. Yathirajan HS, Ashok MA, Narayana Achar B, Bolte M (Apr. 2007) Trifluoperazinium dipicrate. Acta Crystallogr Sect E 63(4):01693-01695. doi:https://doi.org/10.1107/S1600536807009889

11. Harrison WTA, Ashok MA, Yathirajan HS, Narayana Achar B (Jul. 2007) Dioxopromethazinium picrate. Acta Crystallogr Sect E 63(7):03277-03277.

doi:https://doi.org/10.1107/S1600536807029194

12. Anitha K, Athimoolam S, Natarajan S (Sep. 2006) I-Prolinium picrate and 2-methylpyridinium picrate. Acta Crystallogr Sect C 62(9):0567-0570. doi:https://doi.org/10.1107/S0108270106029209

13. Harrison WTA, Bindya S, Ashok MA, Yathirajan HS, Narayana B (Jul. 2007) Imipraminium picrate. Acta Crystallogr Sect E 63(7):o3143-o3143. doi:https://doi.org/10.1107/S1600536807026050

14. Swamy MT, Ashok MA, Yathirajan HS, Narayana B, Bolte M (Dec. 2007) Desipraminium picrate. Acta Crystallogr Sect E 63(12):04919-04919. doi:https://doi.org/10.1107/S1600536807062393

15. Jasinski JP, Butcher RJ, Hakim Al-Arique QNM, Yathirajan HS, Narayana B (Jan. 2010) Imatinibium dipicrate. Acta Crystallogr Sect E Struct Rep Online 66:no. Pt 2, pp. o411-o412. 
doi:10.1107/S1600536810000577

16. Jasinski JP, Butcher RJ, Hakim Al-Arique QNM, Yathirajan HS, Narayana B (Jan. 2010) Chlorimipraminium picrate. Acta Crystallogr Sect E Struct Rep Online 66:no. Pt 2, pp. o347-o348. doi:10.1107/S1600536810000905

17. Li H, Yathirajan HS, Mallesha L, Mohana KN, Narayana B, "Gabapentinium picrate," Acta Crystallogr. Sect. E. Struct. Rep. Online, vol. 65, no. Pt 4, pp. o783-o783, Mar. 2009, doi: $10.1107 /$ S1600536809008952

18. Jasinski JP, Butcher RJ, Hakim Al-Arique QNM, Yathirajan HS, Narayana B (Jul. 2009) Propiverinium picrate. Acta Crystallogr Sect E Struct Rep Online 65:no. Pt 8, pp. 01738-01739. doi:10.1107/S1600536809022995

19. Li H, Hakim Al-Arique QNM, Yathirajan HS, Narayana B, Ramesha AR (Feb. 2009) 4-(4-Carboxy-benzyl)-1-methyl-piperazin-1-ium picrate. Acta Crystallogr Sect E Struct Rep Online 65:no. Pt 3, pp. o518o518. doi:10.1107/S1600536809004474

20. Ramesh P, Akalya R, Chandramohan A, Ponnuswamy MN, "4-tert-Butyl-pyridinium picrate," Acta Crystallogr. Sect. E. Struct. Rep. Online, vol. 66, no. Pt 4, pp. 0999-0999, Mar. 2010, doi: $10.1107 /$ S1600536810011037

21. Jasinski JP, Butcher RJ, Siddegowda MS, Yathirajan HS, Chidan Kumar CS (Jan. 2011) Cinnarizinium dipicrate. Acta Crystallogr Sect E Struct Rep Online 67:no. Pt 2, pp. 0500-o501. doi:10.1107/S1600536811002674

22. Jasinski JP, Pek AE, Siddaraju BP, Yathirajan HS, Narayana B, “Opipramol dipicrate," Acta Crystallogr. Sect. E. Struct. Rep. Online, vol. 66, no. Pt 8, pp. 01979-01980, Jul. 2010, doi: $10.1107 /$ S1600536810026565

23. Dutkiewicz G, Chidan Kumar CS, Yathirajan HS, Narayana B, Kubicki M, "Fluconazolium picrate," Acta Crystallogr. Sect. E. Struct. Rep. Online, vol. 66, no. Pt 10, pp. 02568-o2568, Sep. 2010, doi: $10.1107 /$ S1600536810036329

24. Peng R, Zhao Y, "2-Amino-anilinium picrate," Acta Crystallogr. Sect. E. Struct. Rep. Online, vol. 66, no. Pt 12, pp. 03235-03235, Nov. 2010, doi: 10.1107/S1600536810047057

25. Narayana B, Sarojini BK, Prakash Kamath K, Yathirajan HS, Bolte M, "2-Amino-pyrimidinium picrate," Acta Crystallogr. Sect. E. Struct. Rep. Online, vol. 64, no. Pt 1, pp. 0117-o118, Dec. 2007, doi: $10.1107 /$ S1600536807062599

26. Jasinski JP, Butcher RJ, Siddegowda MS, Yathirajan HS, Ramesha AR (Dec. 2010) Etoricoxibium picrate. Acta Crystallogr Sect E Struct Rep Online 67:no. Pt 1, pp. 0107-o108. doi:10.1107/S1600536810050993

27. Jasinski JP, Butcher RJ, Siddegowda MS, Yathirajan HS, Ramesha AR (Nov. 2010) Levocetirizinium dipicrate. Acta Crystallogr Sect E Struct Rep Online 66:no. Pt 12, pp. 03167-o3167. doi:10.1107/S1600536810045733

28. Jasinski JP, Butcher RJ, Siddegowda MS, Yathirajan HS, Hakim Al-Arique QNM (Jan. 2011) Lomefloxacinium picrate. Acta Crystallogr Sect E Struct Rep Online 67:no. Pt 2, pp. o483-0484. 
doi:10.1107/S1600536811002534

29. Kavitha CN, Jasinski JP, Kaur M, Anderson BJ, Yathirajan HS (Oct. 2014) Crystal structure of 1-(3chloro-phen-yl)piperazin-1-ium picrate-picric acid (2/1). Acta Crystallogr Sect E Struct Rep Online 70:no. Pt 11, pp. o1210-o1211. doi:10.1107/S1600536814023654

30. Yamuna TS, Jasinski JP, Duff CE, Yathirajan HS, Kaur M, “3-(1H-Imidazol-1-yl)propanaminium picrate," Acta Crystallogr. Sect. E. Struct. Rep. Online, vol. 69, no. Pt 10, pp. 01572-01573, Sep. 2013, doi: $10.1107 /$ S1600536813025646

31. Jasinski JP, Butcher RJ, Siddaraju BP, Yathirajan HS, Narayana B (Dec. 2010) Orphenadrinium picrate. Acta Crystallogr Sect E Struct Rep Online 67:no. Pt 1, pp. 0190-o191. doi:10.1107/S1600536810049937

32. Jasinski JP, Butcher RJ, Siddegowda MS, Yathirajan HS, Siddaraju BP (Jan. 2011) Enrofloxacinium picrate. Acta Crystallogr Sect E Struct Rep Online 67:no. Pt 2, pp. o432-o433. doi:10.1107/S160053681100170X

33. Kavitha CN, Kaur M, Anderson BJ, Jasinski JP, Yathirajan HS (Jan. 2014) 1-Piperonylpiperazinium picrate. Acta Crystallogr Sect E Struct Rep Online 70:no. Pt 2, pp. o208-o209. doi:10.1107/S1600536814001524

34. Kavitha CN, Kaur M, Jasinski JP, Yathirajan HS (May 2014) 4-Acetyl-piperazinium picrate. Acta Crystallogr Sect E Struct Rep Online 70:no. Pt 6, pp. 0717-0718. doi:10.1107/S1600536814011726

35. Frisch MJ et al (2016) "G16_C01." p. Gaussian 16, Revision C.01. Gaussian, Inc., Wallin

36. Da Chai J, Head-Gordon M (2008) Long-range corrected hybrid density functionals with damped atom-atom dispersion corrections. Phys Chem Chem Phys 10(44):6615-6620. doi:10.1039/b810189b

37. Gonzalez C, Bernhard H. Schlegel (May 2002) Reaction path following in mass-weighted internal coordinates. J Phys Chem 94(14):5523-5527. doi:10.1021/j100377a021

38. Fukui K (May 2002) The path of chemical reactions - the IRC approach. Acc Chem Res 14(12):363368. doi:10.1021/ar00072a001

39. Yoshida H, Takeda K, Okamura J, Ehara A, Matsuura H (Jan. 2002) A New Approach to Vibrational Analysis of Large Molecules by Density Functional Theory: Wavenumber-Linear Scaling Method. J Phys Chem A 106:14, pp. 3580-3586. doi:10.1021/jp013084m., ",, no.

40. Kolandaivel P, Praveena G, Selvarengan P (2005) Study of atomic and condensed atomic indices for reactive sites of molecules. J Chem Sci 117(5):591-598. doi:10.1007/BF02708366

41. Singh $S$ et al., "Combine experimental and theoretical investigation on an alkaloidDimethylisoborreverine," J Mol Struct, 1103, 2016, doi:10.1016/j.molstruc.2015.09.021

42. Karthick T, Tandon P, "Computational approaches to find the active binding sites of biological targets against busulfan,” J Mol Model, 22, 6, 2016, doi:10.1007/s00894-016-3015-z

43. Stachowicz-Kus̈nierz A, Korchowiec J (2016) Nucleophilic properties of purine bases: Inherent reactivity versus reaction conditions. Struct Chem 27(2):543-555. doi:10.1007/s11224-015-0583-y 
44. Richard FW, Bader, Atoms in Molecules A Quantum Theory. Clarendon Press, 1994

45. Karthick T, Tandon P, Srivastava K, Singh S (2018) Evaluation of non-covalent interactions of chlorambucil (monomer and dimer) and its interaction with biological targets: Vibrational frequency shift, electron density topological and automated docking analysis. Arab J Chem 11(5):591-608. doi:https://doi.org/10.1016/j.arabjc.2017.10.012

46. Brovarets' OO, Voiteshenko IS, Pérez-Sánchez H, Hovorun DM (2017) A QM/QTAIM research under the magnifying glass of the DPT tautomerisation of the wobble mispairs involving 2-aminopurine. New J Chem 41(15):7232-7243. doi:10.1039/C7NJ00717E

47. Kross RD, Fassel VA (Jan. 1957) Regularities in the Infrared Spectra of Picric Acid Molecular Complexes1. J Am Chem Soc 79(1):38-41. doi:10.1021/ja01558a008

\section{Figures}

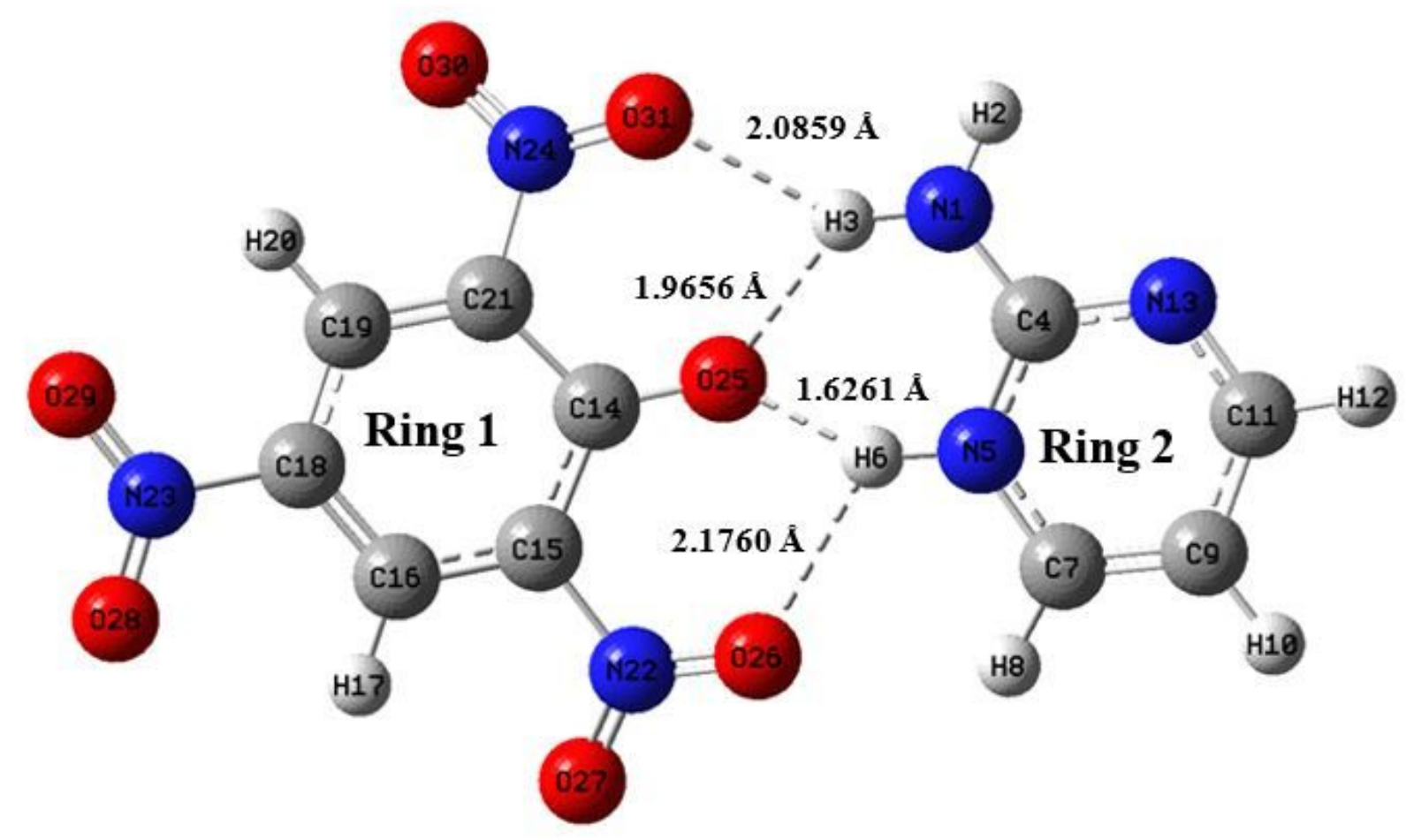

\section{Figure 1}

The optimized structure of isomer 1 of 2APP. The dotted line illustrates the hydrogen bonds formed between the picrate and pyrimidine ring. 


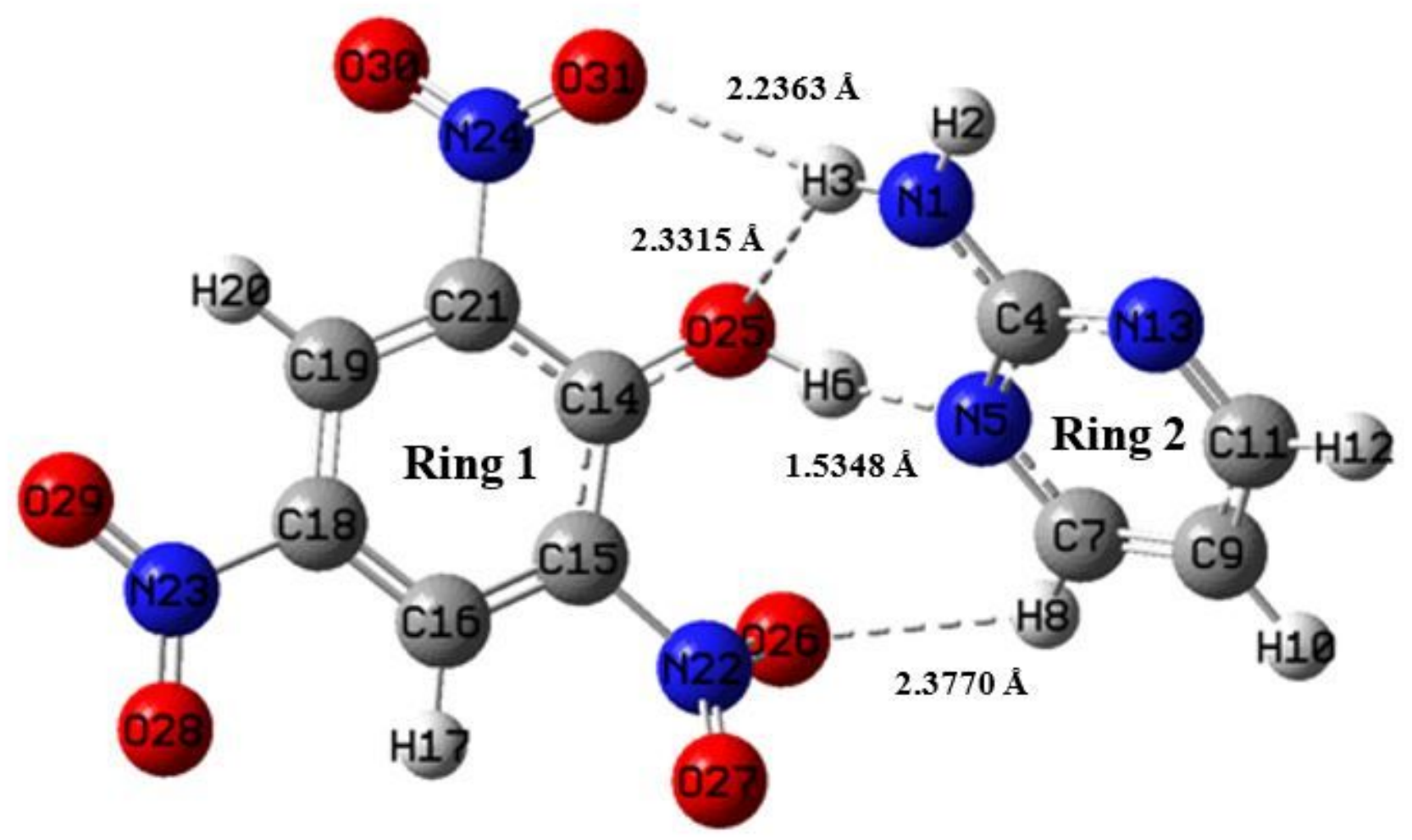

Figure 2

The optimized molecular structure isomer 2 of 2APP. The dotted line illustrates the hydrogen bonds formed between the picrate and pyrimidine ring.

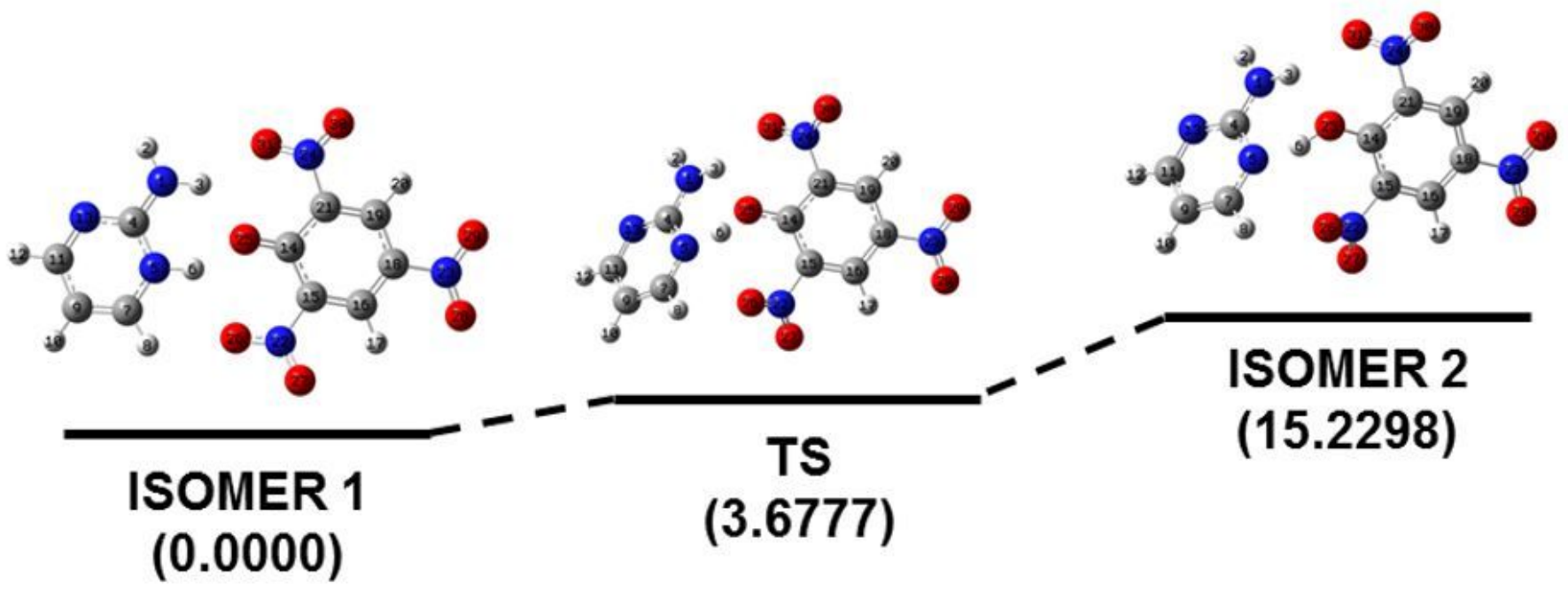

Figure 3

Systematic potential energy diagram for the formation of isomer 2 form the isomer 1 calculated at WB97XD/6-311++G (d, p) level of theory. Relative energies of the structures with respect to isomer 1 in 


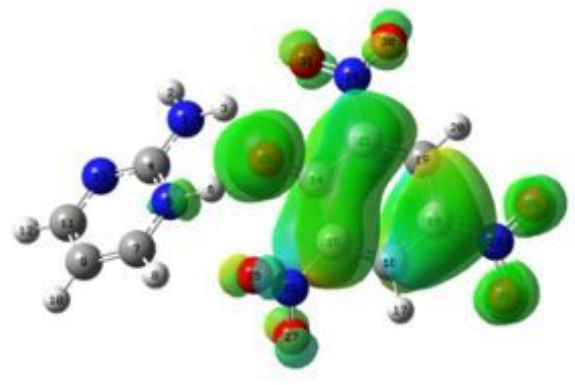

3

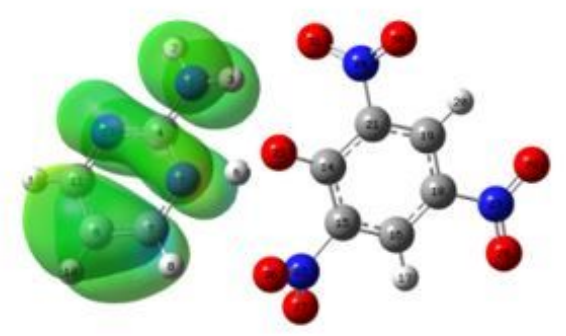

0

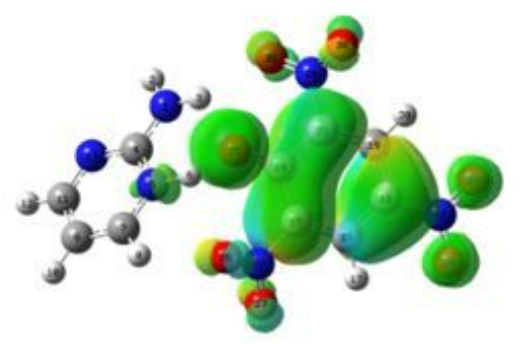

2

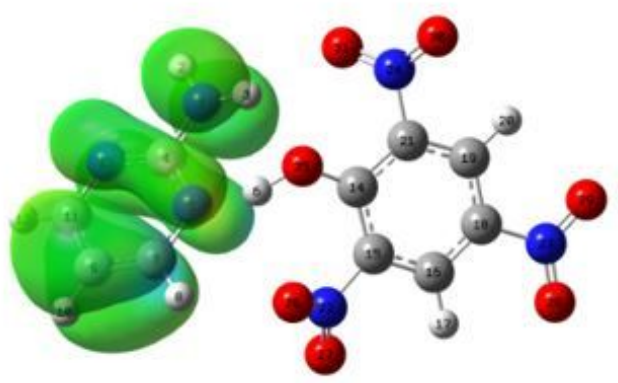

$-1$

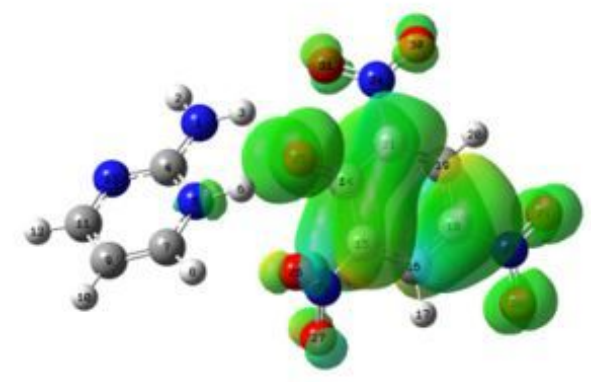

1

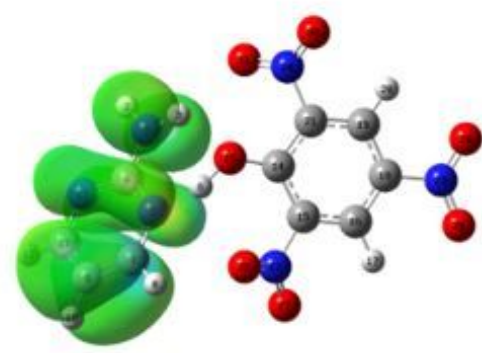

$-2$

\section{Figure 4}

Highest occupied molecular orbital of few points from the reactant and product side of IRC. Point 3 is reaction complex (isomer 1 ), point 0 is transition state, and point -2 is the product complex (isomer 2), the surfaces of the points 2,1 , and -1 corresponds to intermediary structures.
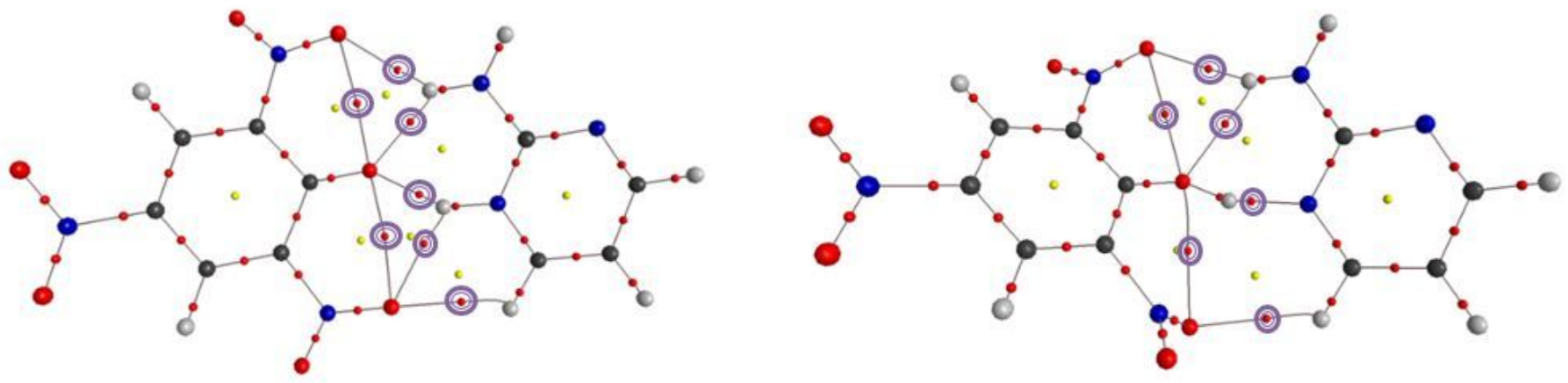

Figure 5

Molecular graphs illustrating the non-bonded interactions of 2APP isomers 1 and 2 . The BCPs corresponding to the non-bonded interactions are circled with purple color. 


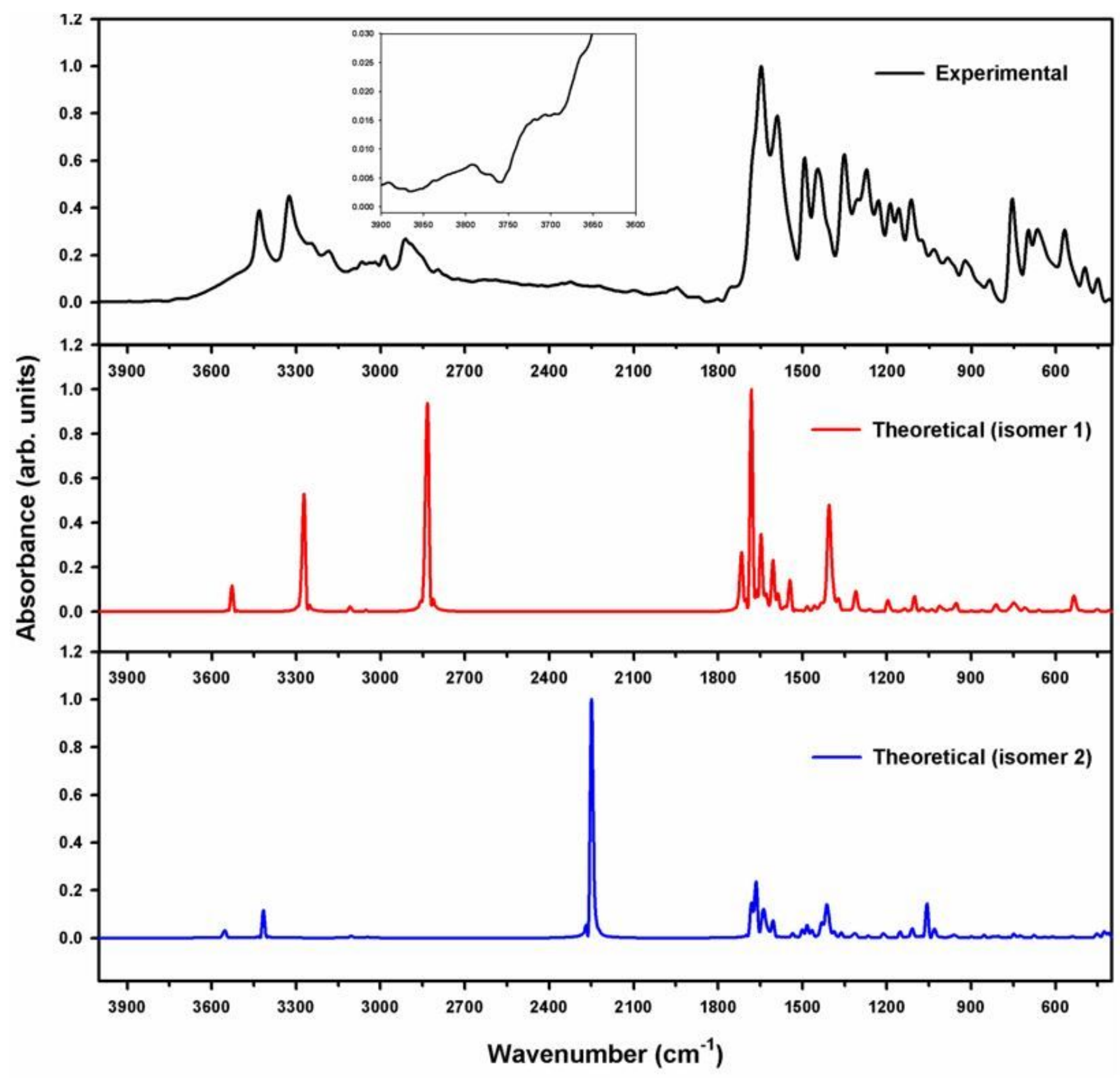

Figure 6

Experimental FT-IR spectrum of 2APP in the solid phase and theoretically simulated IR spectrum of isomer 1 and 2. 


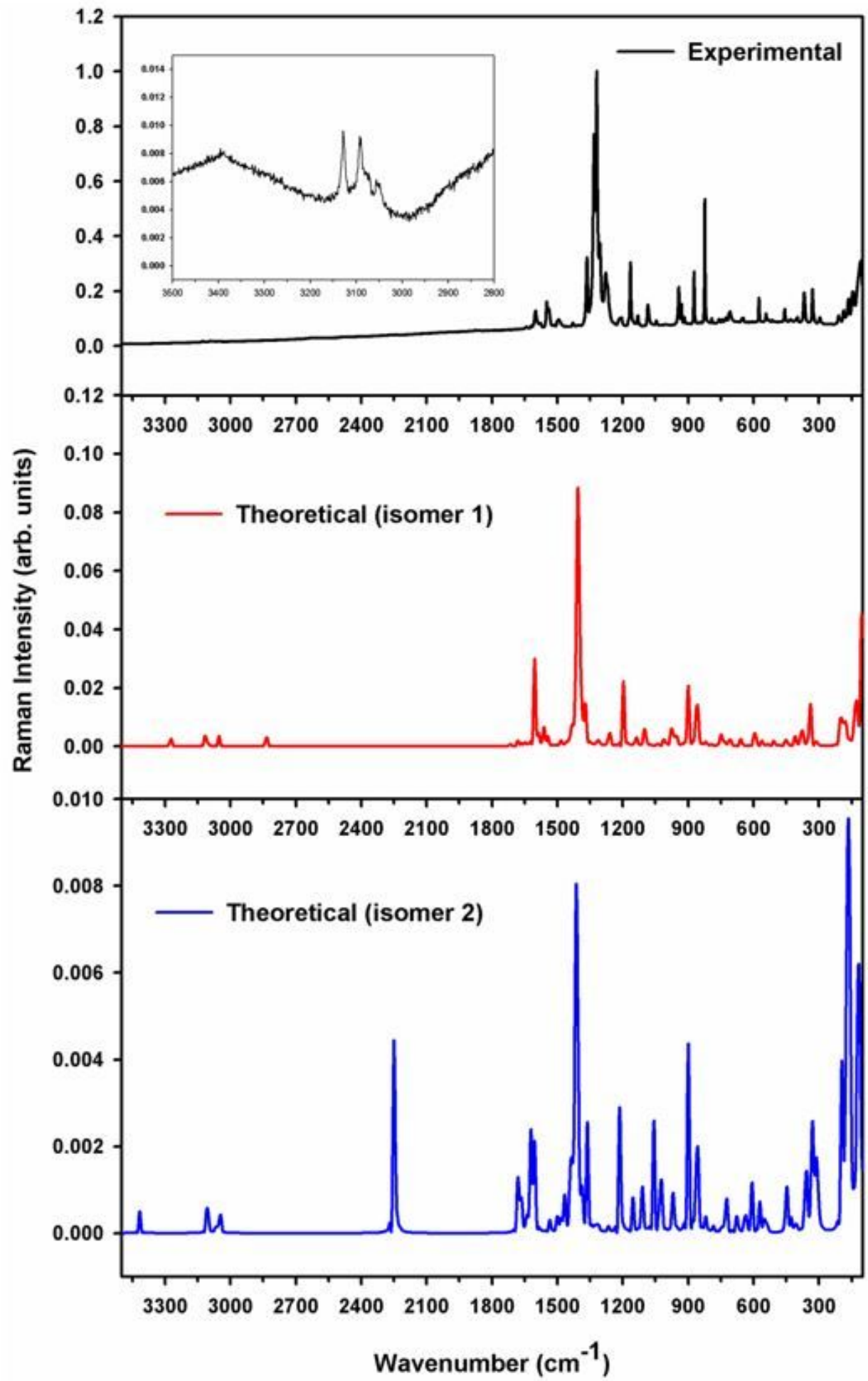

Figure 7

Experimental FT-IR spectrum of 2APP in the solid phase and theoretically simulated IR spectrum of isomer 1 and 2.

\section{Supplementary Files}


This is a list of supplementary files associated with this preprint. Click to download.

- SupplementaryMaterial.docx 